\title{
Single-Crystal X-ray Diffraction at High Pressures
}

\author{
C. Weir, S. Block, and G. Piermarini
}

\begin{abstract}
(July 23, 1965)
Construction and operation of a high-pressure single-crystal x-ray diffraction precession camera is described. The instrument appears applicable to single crystal studies to pressures as high as at least 30 kilobars and temperatures of at least $250{ }^{\circ} \mathrm{C}$. Application of the instrument is illustrated by single crystal studies of ice VI and ice VII. Unit cell parameters are given for these two forms of ice. Further modifications and applications are discussed.
\end{abstract}

Key Words: High pressure, single crystal, x-ray diffraction, ice VI, ice VII, water, calcite.

\section{Introduction}

$\mathrm{X}$-ray diffraction of materials under high pressures presents obvious experimental problems arising from the necessity of using a vessel which is transparent to $\mathrm{x}$ rays, but sufficiently strong to contain the pressures desired. Jacobs $[1]^{1}$ fabricated a steel vessel equipped with beryllium windows and used helium as the pressure medium in his pioneering studies, but little additional progress was made until Lawson [2] conceived and used the diamond pressure vessel. Imposing progress has been achieved in recent years, and the problem of x-ray diffraction appears to be solved in principle up to pressures as high as several hundred kilobars with accompanying temperatures as high as $1000{ }^{\circ} \mathrm{C}[3,4,5]$. In practice, however, the diffraction data are limited in diffraction angle and further to those reflections sufficiently strong to override the unavoidable background arising from scattering by the pressure cell itself. All significant work, to date, involves powder x-ray diffraction and, in view of the present limitations of the methods, there is little promise that unequivocal structures of any high pressure phases, except those of the utmost simplicity, can result from such methods.

Some high-pressure polymorphs can be stabilized at 1 bar by quenching to low temperatures while still under pressure. Both powder and single-crystal x-ray diffraction studies [6-12] have been made on several such materials in the metastable state. As it appears that only a limited number of presently known high pressure polymorphs are quenchable, there is a need for producing and studying single crystals of high pressure phases in their ranges of stability by means of $x$ rays. This paper is a preliminary report of techniques developed for single-crystal x-ray diffraction at high pressures.

'Italicized figures in brackets indicate the literature references at the end of this paper

\section{Apparatus and Experimental Method}

\subsection{Apparatus}

The instrument used for single crystal studies is the diamond-anvil high-pressure cell developed at NBS. This cell has been used here and in other laboratories for spectroscopy, microscopy, and powder diffraction studies $[13,14,15]$. A technique for mounting a metal gasket between the diamond anvil faces was developed by Van Valkenburg [16] which permits the application of pressure to liquids. Using this technique it is possible to grow single crystals from liquids under pressure or to subject a single crystal immersed in the liquid to purely hydrostatic pressure. The modifications of the cell and the ordinary precession camera to permit high-pressure single crystal studies are as follows:

The original cell designed for spectroscopy [13] has been improved and is shown in figure 1 . The instrument has opposed diamond anvils, A, to generate pressure. The anvils are fabricated from gem quality diamonds by grinding small flat surfaces approximately $0.6 \mathrm{~mm}$ and $1.2 \mathrm{~mm}$ in diameter parallel to the table faces. The diamonds are seated on their table faces in recesses in metal plates, B, that are held to cylinders, C, by means of two screws $180^{\circ}$ apart. Two other screws at an angle of $90^{\circ}$ to the holding screws permit alinement of the diamond anvil surfaces. The cylinders fit snugly into bearing, D, which has a shoulder at one end to support the thrust applied to the cylinder. The thrust which forces the anvils together is supplied by plate, E, by means of spring, F, acting through top plate, G, and lever arms, $H$. The diamond support plates, B, have always been made of stainless steel, but, for reasons to be discussed later, have been replaced by high purity beryllium plates. In both cases, a central hole is drilled in each plate to permit microscopic 


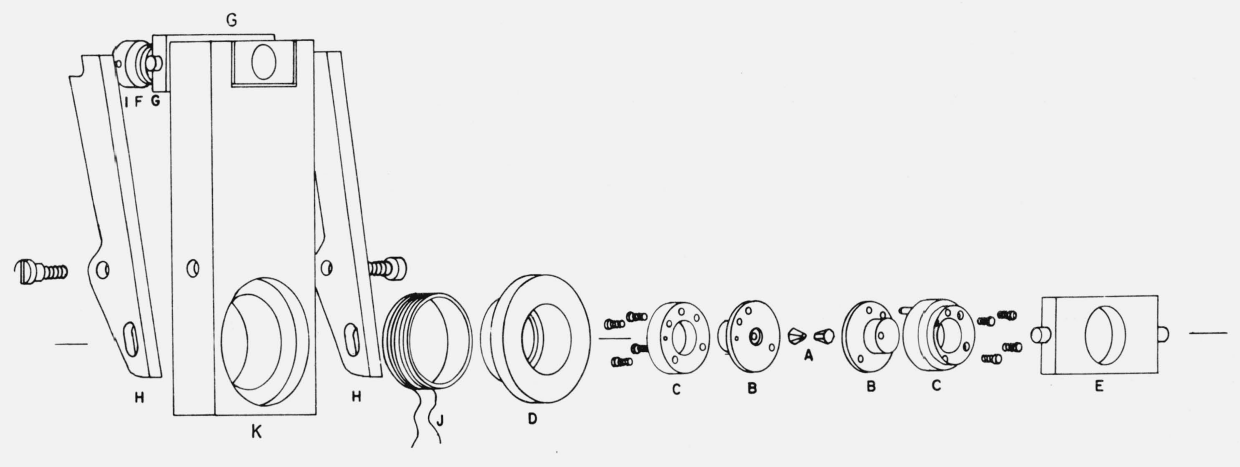

FIGURE 1. Construction details of diamond cell (not to scale).

observation of the specimen. To permit the entry or exit of $\mathrm{x}$ rays at higher angles, it was necessary to machine the stainless steel plates out at an angle of about $45^{\circ}$. Beryllium metal is relatively transparent to the $\mathrm{x}$ rays used here, and angular relief is not required. Due to spatial limitations the usual knurled knob on the screw, was replaced with a disk, I, which could be turned by means of a removable crank. Elevated temperatures were obtained by means of a small furnace, J. The furnace was made by winding Nichrome wire on a ceramic sleeve which fit snugly over the outside of $\mathrm{D}$ and inside the block, K. Temperature was recorded and controlled by means of a thermocouple inserted through a small hole in one of the cylinders, $\mathrm{C}$, and plate, B, so as to be in direct contact with the metal gasket placed between the diamonds. An automatic recording-controlling unit was used to monitor temperatures.

It was necessary to modify the commercial precession camera to sustain the weight of the diamond cell. The existing crystal bearing assembly was eliminated by removing the mounting pillar and replaced by a sturdier unit constructed of aluminum to minimize its weight. An aluminum alloy shaft 1 in. in diameter was coupled to the film precession shaft as in the original camera. A large graduated flange was fitted over the end of the shaft and locked in place by means of set screws. This flange replaced the original "dial." A modified goniometer head was fastened to the other end of the flange. This provided only a single arc correction in an approximate horizontal plane. The two sections of this arc were also locked together with set screws. The customary vertical arc could not be accommodated in the available space and was eliminated. A stout horizontal bar clamped to the arc correcting unit was used to mount the diamond cell. This bar could be moved on a track with positioning screws to permit adjustment in the direction parallel to the x-ray beam. Vertical motion of the cell was achieved by means of a plate fastened to the diamond cell with slotted screw holes and sliding on a vertical track. The cell was clamped to the horizontal bar by screws into this plate. The screw holes through the horizontal bar were also slotted to permit the cell to slide on a track on the bar. This assembly permitted translation along three mutually perpendicular axes, and rotation about two mutually perpendicular axes. Because of interference between the cell and the $\mathrm{x}$-ray tube or the collimator support, and limitations imposed by the metal of the cell cutting off the x-ray beam, maximum angular corrections of the order of $\pm 15^{\circ}$ were permitted.

On assembly it was necessary to aline the new precession axis and the diamond cell to this precession axis. Most of the operations required are obvious and only the operations required to locate the specimen on the precession axis will be described. It was found that vertical and lateral adjustments were most easily initiated by visual alinement of the gasket hole with the collimator with $\bar{\mu}=0$. The gasket hole can be observed through the diamond. Refinements in these adjustments were made by maximizing the intensity in the spot produced by the $x$ rays on a fluorescent screen placed behind the diamond cell. The intensity was first maximized at $\bar{\mu}=0$ and final adjustments were made at higher values of $\bar{\mu}$. The adjustment of the cell in the direction parallel to the $\mathrm{x}$-ray beam was achieved by eliminating doubling of diffracted spots.

In use, it was expedient to remove the cell frequently for microscopic observation, and it was found to be essential to provide a means of ensuring that the cell was replaced in the same position to eliminate the need for realinement. This was achieved by means of the track on the horizontal bar which fixed the vertical and one lateral position and by means of metal stops on the bar which fixed the other lateral position. With these guides the cell could be removed 


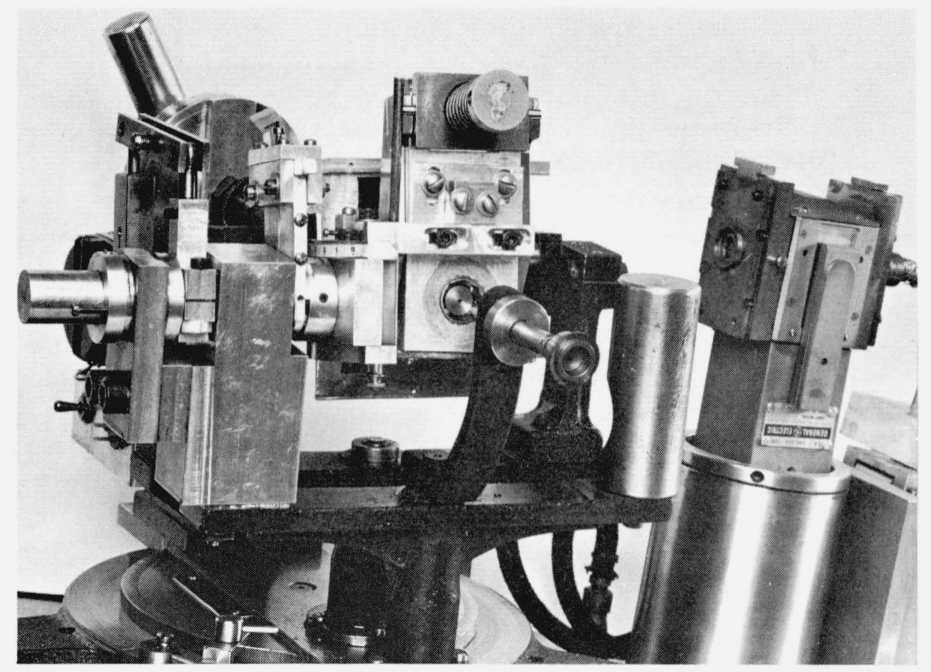

Figure 2. Assembled single crystal precession unit.

and replaced in a few seconds with no alinement adjustments required. The mounted cell is shown in figure 2 .

For the diamond cell and camera used here it was found that with dial and arc readings near zero, the maximum useful value of $\bar{\mu}$ was about $20^{\circ}$ with steel plates and $30^{\circ}$ with beryllium plates. As the dial and arc values increased the maximum useful $\bar{\mu}$ value decreased. With the beryllium plates, however, values of $20^{\circ}$ were easily obtained at the maximum arc and dial settings available.

\subsection{Sample Preparation}

The initial step in sample preparation involves fabricating the metal gasket. A thin sheet of metal $(0.010$ in. $\times 0.25$ in. $\times 0.25$ in. $)$ is subjected to an initial compression between the diamond anvils to produce a well-defined indentation of the smaller of the two diamond surfaces. The pressure required for this operation must be adjusted to the properties of the gasket material and may vary from 5 kbar -60 kbar for different metals. Under a low power microscope a small punch mark is made in the center of the indentation and a small hole (No. 80 drill) is drilled through the gasket using the punch mark for centering. For pressure work above about $15 \mathrm{kbar}$ it is essential that this hole be centered in the indentation to minimize the failure of the gasket; at lower pressures the centering requirement is less stringent. The burrs formed in drilling are removed with a small jeweller's file and the gasket is placed over the small diamond using the indentation as a guide. In this operation the cylinder containing the small diamond should be in position in the diamond cell with the diamond anvil face uppermost. If a liquid is to be studied a small drop of liquid is placed on top of the gasket in contact with the hole, the cylinder with the larger diamond inserted and the cell carefully assembled to avoid displacing the gasket. If a solid is to be studied, the selected single crystal may be placed in the hole and oriented on the diamond surface with a small needle before the hydraulic liquid is applied or the liquid may be applied first and the crystal inserted through the liquid. In either case difficulties are to be expected in maintaining proper alinement of the crystal during the assembly of the cell and the initial application of pressure. One technique used here involves cementing the gasket and the crystal in position by means of thin Canada balsam before assembly. However, cements are considered to be undesirable because they interfere with microscopic observations and may prove to be a source of pressure gradients.

Liquids which have been used successfully are water, glycerine, methanol, and Varsol. Both water and Varsol crystallize at moderate pressures, but glycerine and methanol or glycerine-water mixtures apparently do not crystallize to about 30 kbar. Glycerine proves to be sufficiently viscous to prevent appreciable motion of a crystal during the assembly process. Of these liquids, water, glycerine, and methanol are relatively incompressible, a matter of some importance because the crystal is crushed if it comes in contact with both diamond anvil surfaces simultaneously.

Some iron and nickel alloys serve to make satis. factory gaskets provided pressures above about 15 to $20 \mathrm{kbar}$ are not required. Brass and aluminum alloys are not useful to these pressures but might prove useful at lower pressures. Above about 20 kbar problems involving gasket blowout are experienced, presumably because the strength of the metal and the diamond-metal friction is exceeded by the pressure exerted by the liquid. Two solutions are indicated, one to increase the strength of the metal gasket, the other to increase the surface area of the diamonds. Both techniques appear to be effective. 
When molybdenum metal gaskets were used no blowouts were experienced. Molybdenum appears to be more difficult to handle mechanically but is very ductile under pressure (see Bridgman [17]). When the diameter of the smaller diamond was increased from $0.6 \mathrm{~mm}$ to $0.8 \mathrm{~mm}$ no blowouts were experienced using a nickel alloy gasket. The optimum gasket thickness for the diamonds used here appears to be about $0.010 \mathrm{in}$. Thicker gaskets have been used but do not perform satisfactorily, presumably because of the nonuniform shape of the smaller diamond. This diamond penetrates the gasket and appears to produce nonuniform stresses in the metal resulting in distortion and frequent blowout of the gasket hole. Gaskets 0.005 in. in thickness perform satisfactorily but provide a smaller available volume.

lnitally, experiments were conducted using Mo $\mathrm{K} \alpha$ radiation. Under these conditions orientation photographs were obtained in $1 / 4$-hr with ordinary $\mathrm{x}$-ray film. With this radiation, however, it was found that cone axis, and upper level photographs were not satisfactory because the diffracted beams at higher angles were blocked by the cylinders or the instrument itself. A marked improvement in quantity of data obtained has resulted from using $\mathrm{Ag} \mathrm{K} \alpha$ radiation which has a shorter wavelength $(0.5609 \AA$ versus $0.7107 \AA)$. With $\mathrm{Ag}$ radiation useful cone axis and upper level photographs as high as the second level have been obtained with $\mathrm{Fd}^{*} \approx 4$. Using Ag radiation, however, some sacrifice in exposure time is required. By using fast film (such as Kodak No Screen or DuPont Cronex III) in conjunction with fluorescent screens (Cronex CB 2, Ilford, or Radelin TF) ${ }^{2}$ placed behind the film, orientation photographs can be made in 1/4-hr. Exposures are increased to at least $\mathrm{l} \mathrm{hr}$ without the fluorescent screen.

It should be noted that the problem of collimation is simplified by use of a metal gasket that is opaque to the $\mathrm{x}$ rays. The hole in the gasket functions as a second pinhole and the external collimator need only contain a single pinhole. Use of the gasket as part of the collimating system produces diffraction rings from the metal in the resulting pattern. These rings have not caused any difficulties in interpreting the films. Extensive collimation of the beam before it is incident on the specimen and centering of the beam in the gasket hole can be used to eliminate diffraction rings from the metal. However, this technique results in a marked increase in exposure time which does not appear to be justified by the results.

\section{Results}

Initial studies using this instrument were made on materials which were crystalline solids at 1 bar and had known transitions at elevated pressures. The experimental technique used was to orient a crystal-

${ }^{2}$ Certain commercial materials and equipment are identified in this paper in order to adequately specify the experimental procedure. In no case does such identification imply recommendation or endorsement by the National Bureau of Standards, nor does it imply that the material or equipment identified is necessarily the best available for the purpose. lographic plane of the low pressure form using the precession camera. The pressure cell was then removed from the camera and mounted on a polarizing microscope. The pressure was increased slowly until the transition was observed by noting an abrupt change in birefringence or dimensions or a fracturing of the crystal. If the crystal remained intact in the high pressure form, the cell was returned to the camera for precession photographs. Under the conditions used to date, only one material of those studied appears to remain in single crystal form through the transition. The transition $\mathrm{CaCO}_{3}$ (calcite) $\rightarrow \mathrm{CaCO}_{3} \mathrm{II}$, [18] occurs with a marked change in birefringence and the crystal frequently remains intact. The transition $\mathrm{CaCO}_{3} \mathrm{II}-\mathrm{CaCO}_{3} \mathrm{III}$ always results in a polycrystalline specimen. Transitions in $\mathrm{KNO}_{3}$ [19] and the alkali halides [20] invariably produced polycrystalline products and no transition could be detected in $\mathrm{KIO}_{4}[21]$.

In only one experiment with calcite was it possible to obtain a photograph of a densely populated plane of the $\mathrm{CaCO}_{3} \mathrm{II}$ form. Zero level and cone axis photographs could be interpreted on the basis of a cell with dimensions $a=4.97 \AA, b=7.72 \AA$, and $c=13.25 \AA$ with the $a$ and $b$ axes orthogonal. No information on any other angles or on upper levels could be obtained. Characteristic absences $h+k=2 n+1$ were observed on the zero level photograph. Davis [22] has reported powder diffraction data on $\mathrm{CaCO}_{3} \mathrm{III}$ and noted that $\mathrm{CaCO}_{3} \mathrm{II}$ gave diffraction data similar to ordinary calcite except that the 113 reflection was missing in $\mathrm{CaCO}_{3} \mathrm{II}$. With the parameters found here and assuming an orthorhombic cell, it is possible to index almost all the lines reported for $\mathrm{CaCO}_{3} \mathrm{I}$ (calcite), $\mathrm{CaCO}_{3} \mathrm{II}$, and $\mathrm{CaCO}_{3} \mathrm{III}$ within the probable errors of the data. Further study is necessary before this situation can be cleared up. However, calcite crystals present problems in orientation because of their cleavage characteristics and it was decided to defer further studies until an improved instrument becomes available.

From the limited studies conducted here on solidsolid transitions at room temperature in single crystals, it appears that rentention of the single crystal form through a high pressure transition will not occur as frequently as originally anticipated. Other techniques for production of high pressure polymorphs in single crystal form are available, such as crystallization from solution or from a melt under conditions of stability of the desired polymorph. Both techniques are possible with the present instrument which has an upper temperature limit of operation above $250{ }^{\circ} \mathrm{C}$. Neither method has been attempted because of the great ease with which single crystals may be grown from materials normally liquid at 1 bar and room temperature and current interest in the structure of such crystals.

\subsection{Ice}

Bridgman $[23,24]$ has shown that six forms of ice are formed under pressure. Of these six forms only two, ice VI and ice VII, are formed from water at or 
above room temperature. Ice VI crystallizes from water at room temperature and approximately 9 kbar and ice VII forms at pressures above about $22 \mathrm{kbar}$ and $82{ }^{\circ} \mathrm{C}$ - the VI-VII-L triple point. Both ice VI and ice VII can be grown as single crystals in the diamond cell, ice VI growing readily but ice VII with considerable difficulty.

\subsubsection{Ice VI}

Powder diffraction data for ice VI have been reported by Bertie, Calvert, and Whalley $[8]$ at $90{ }^{\circ} \mathrm{K}$ and $\mathbf{I}$ bar and by Kamb and Davis [25] at $-50{ }^{\circ} \mathrm{C}$ and 8 kbar. Both reports agree reasonably well on the powder lines and relative intensities when allowance is made for the different conditions of the two measurements. From single crystal studies here a preliminary report has been given for a unit cell which can be used to index the observed powder diffraction data [26].

Typical precession photographs of a single crystal of ice VI are shown in figures $3-7$, with figures 3,4 , and 5 being made with steel plates on the cylinders and figures 6 and 7 with beryllium plates. A typical orientation photograph using unfiltered Ag radiation with a fluorescent screen is shown in figure 3 . The exposure time is $1 / 2$-hr with $\bar{\mu}=10^{\circ}$. The intense streaks and loops are contributed by the diamonds, the diffraction rings by the metal gasket, and the narrow streaks by ice VI. A zero level photograph using $\mathrm{Pd}$ filtered $\mathrm{Ag}$ radiation is shown in figure 4. This is a $72 \mathrm{hr}$ exposure with $\not=16^{\circ}$ and a layer level screen $11.5 \mathrm{~mm}$ in diameter at a spacing of $40 \mathrm{~mm}$. It is apparent that the filter and the layer level screen eliminate most of the diamond interference. It will be observed that diffraction spots in the 4th quadrant of this photograph are weaker than those in the $2 \mathrm{~d}$ quadrant as a result of shadowing by the instrument itself. This occurred because of the angular correction required to orient the crystallographic plane. The first level spots are diffracted at higher angles than those on the zero level and the shadowing by the instrument makes it much more difficult to photograph these levels as shown by figure 5 . This is the lst level corresponding to figure 4 and is a $72 \mathrm{hr}$ exposure with $\bar{\mu}=10^{\circ}$. There are several rows of diffraction spots in this photograph concentrated principally in the $2 \mathrm{~d}$ quadrant. The third quadrant which was slightly shadowed in the zero level photograph is now completely empty of diffraction spots. The shadowing restricts both the diffraction angle and the precession angle and for this reason it was decided to replace the steel plates, B, of figure 1 with beryllium plates. The effects of the substitution may be ascertained by comparing figures 4 and 5 with figures 6 and 7 which made use of the beryllium plates. The latter two photographs are $48 \mathrm{hr}$ exposures with $\bar{\mu}=22^{\circ}$ and $\bar{\mu}$ $=10^{\circ}$ respectively. A higher background is noted in the latter two photographs presumably arising from incoherent scattering by the approximately 1/2-in. of polycrystalline Be traversed by the x-ray beam.

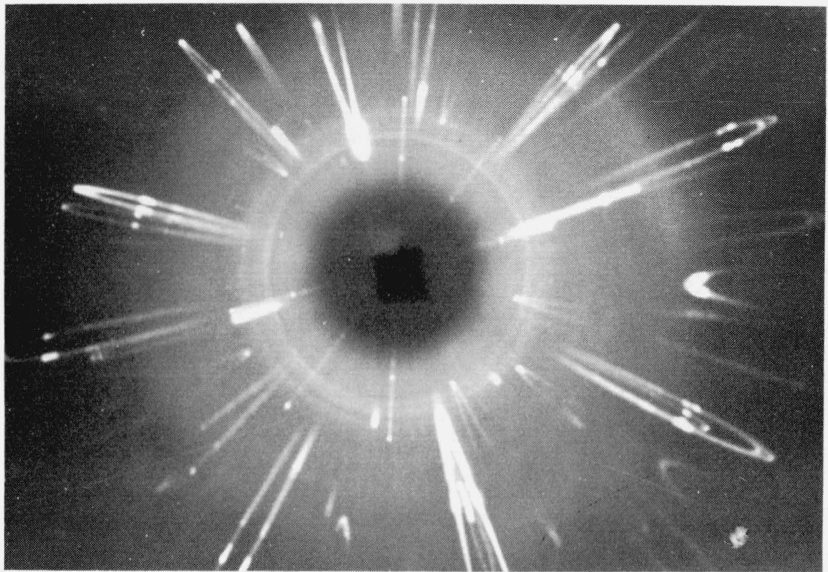

FIGURE 3. Typical orientation photograph (unfiltered Ag radiation using fluorescent screen; $\bar{\mu}=10^{\circ} ; 1 / 2 \mathrm{hr}$ exposure.

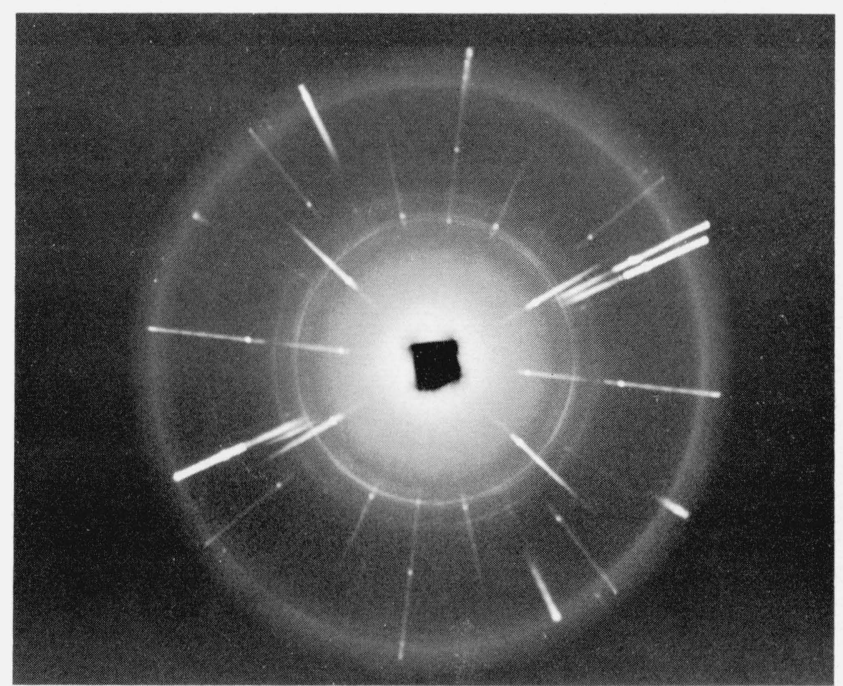

FIGURE 4. Ice VI-hk0 photograph with steel plates (Pd filtered Ag radiation; $\bar{\mu}=16^{\circ} ; 72 \mathrm{hr}$ exposure).

However, no appreciable shadowing is apparent on either photograph. With the beryllium plates shadowing becomes important on the $2 \mathrm{~d}$ level of this crystal but even on this level several reflections were obtained whereas none were obtained with the steel plates. It is of interest to note the threefold diamond axis in figure 6 .

Final answers on the unit cell and symmetry for ice VI have not been obtained to date. The unit cell dimensions at room temperature and approximately 9 kbar are $a=8.38 \AA, b=6.17 \AA, c=8.71 \AA$ with uncertainties of $0.05 \AA$ in all cases. It is assumed that these axes are orthogonal. From the $h k 0$ films systematic absences are $h k 0, h=2 n+1$, and $k=2 n+1$. From $h k 1$, systematic absences are $h+l=2 n+1$. From upper level photographs and upper level loops seen on zero level photographs it appears that $a$ is a true twofold axis but $b$ is not. To give an unequivocal space group requires more facility of orienting 


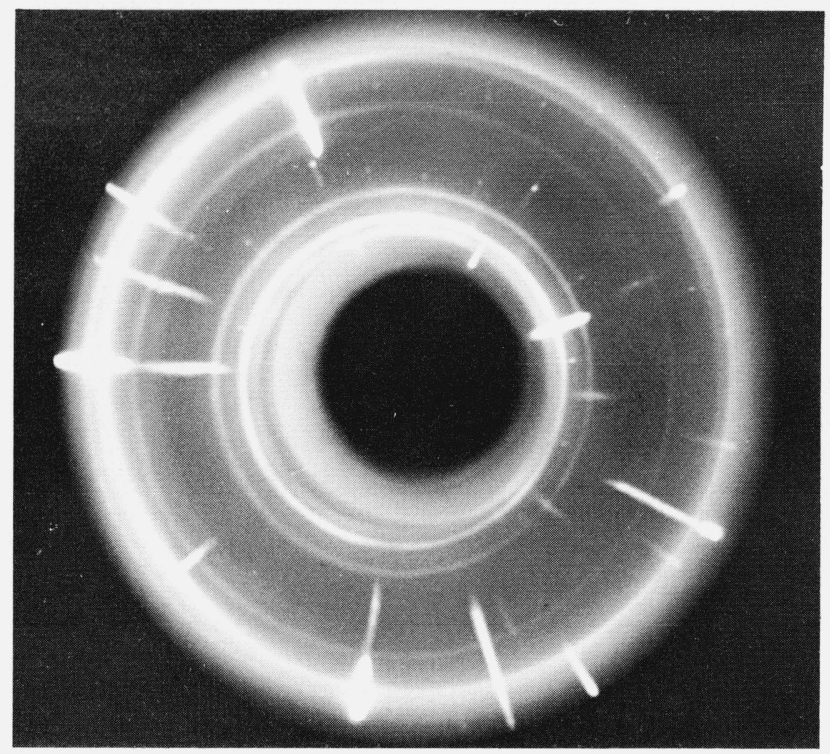

FigURE 5. Ice VI-hkl photograph with steel plates (Pd filtered Ag radiation; $\bar{\mu}=10^{\circ} ; 72 \mathrm{hr}$ exposure $)$.

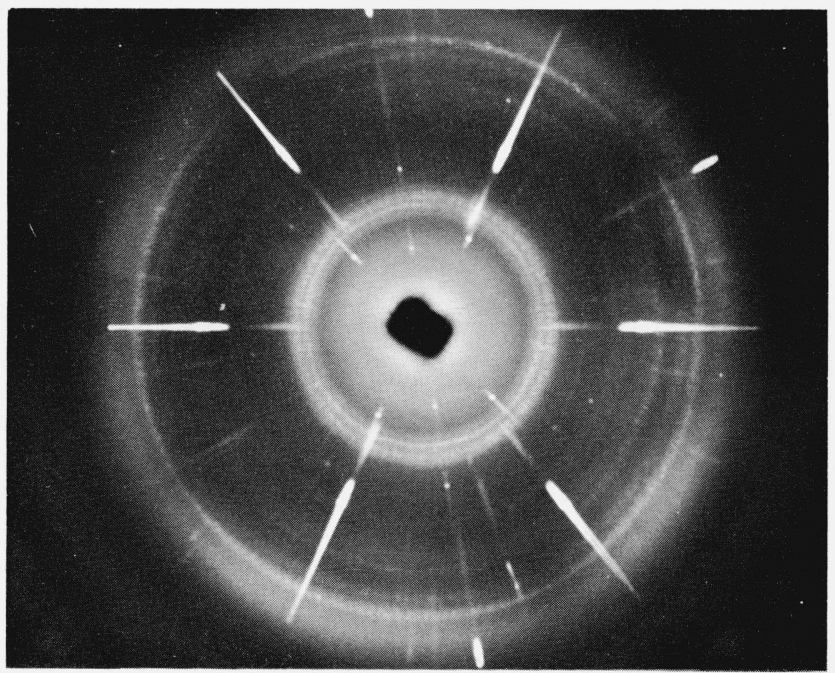

FigURE 6. Ice VI-hk0 photograph using beryllium plates (Pd filtered Ag radiation; $\bar{\mu}=22^{\circ} ; 48 \mathrm{hr}$ exposure .

the crystal and less difficulty with shadow produced by the cell. A new camera now under construction is expected to facilitate solution of this problem.

\subsubsection{Ice VII}

Bertie, Calvert, and Whalley [8] and Kamb and Davis [25] have reported powder diffraction data for ice VII. The former authors worked at $90{ }^{\circ} \mathrm{K}$ and 1 bar and the latter at $-50{ }^{\circ} \mathrm{C}$ and 25 kbar. Bertie,

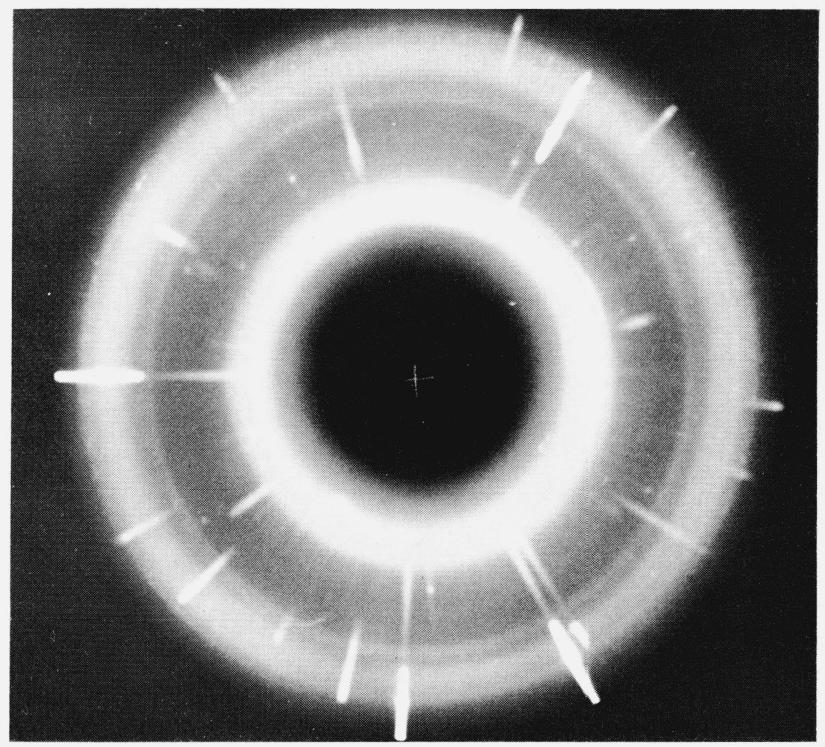

FIGURE 7. Ice VI-hkl photograph using beryllium plates (Pd filtered Ag radiation; $\bar{\mu}=10^{\circ} ; 48 \mathrm{hr}$ exposure).

Calvert, and Whalley reported more reflections than Kamb and Davis, but noted that their strong reflections could be indexed in the cubic system. Kamb and Davis concluded that all their reflections were consistent with a body-centered cubic cell with $a=3.30 \AA$, and they have proposed this structure for ice VII. Single crystal studies of ice VII in this laboratory arrived at identical conclusions at about the same time.

Single crystals of ice VII were grown in the diamond cell at approximately $90{ }^{\circ} \mathrm{C}$ and 25 kbar. The crystal grew as an anhedral spherical globule and was cooled to room temperature for study. It was found that very slow cooling was essential to prevent fracturing the crystal. Three different orientations of ice VII have been studied showing reciprocal lattice, planes perpendicular to the [100] and the [111] axes, and a plane containing the [110] and [121] axes. This latter plane was derived from the orientation perpendicular to the [111] axis by angular corrections consistent with the body-centered cell proposed by Kamb and Davis [25]. There are few reflections observed and the intensities decrease very rapidly with increasing order as noted by Kamb and Davis [25]. No weak reflections indicative of lower symmetry or superlattice have been observed, although it should be noted that the small dimensions of the unit cell precluded upper level photographs. From the present data, it is concluded that the cell is cubic with $a=3.40 \pm 0.05 \AA$. Systematic absences $h+k$ $+l=2 n+1$ indicate a body-centered cell.

Bridgman [27] observed that water at $25{ }^{\circ} \mathrm{C}$ undergoes a change in volume of $0.359 \mathrm{~cm}^{3} / \mathrm{g}$ between 1 bar and 25 kbar. Therefore, the measured density of ice VII at $25 \mathrm{kbar}$ and $25^{\circ} \mathrm{C}$ is $1.56 \mathrm{~g} / \mathrm{cm}^{3}$. From the dimensions of the unit cell obtained here contain- 
ing two molecules of water the calculated density is $1.51 \mathrm{~g} / \mathrm{em}^{3}$. The single crystal data, therefore, corroborate the body-centered cubic structure proposed for ice VII by Kamb and Davis [25].

\section{Conclusions}

The present studies have shown that successful single-crystal $\mathrm{x}$-ray diffraction work at high pressures is possible to pressures of at least 30 kbar. Successful structure analyses and space group determinations require more data and greater precision and facility of operation than the present precession camera can provide. A new goniometer head providing all the usual angular and translational motions and designed to support the weight of the diamond cell is being constructed. In addition, a new diamond cell constructed entirely of high purity beryllium metal is being fabricated.

Note added in proof: In relation to the structure of ice VI (see section 3.1.1) Kamb has recently published (Nature 150 205, (1965)), x-ray diffraction data on ice VI obtained at 1 bar and $-175^{\circ} \mathrm{C}$. He concluded that the cell was tetragonal with dimension $a=6.27 \AA$ and $c=5.79 \AA$. This cell differs from the preliminary cell presented here although the two cells are related. However, there is sufficient difference that the cell proposed by Kamb cannot index both the $3.4 \AA$ and $3.6 \AA$ lines reported in the powder pattern by Bertie, Calvert, and Whalley [8] which the present cell can do. We have recently obtained an improved cell and orient-

(Paper 69C4-208) ing device. The final answer to the cell of ice VI under equilibrium conditions has not been obtained, but, by reorienting about our $b$ axis we have obtained a zero level pattern which shows a four-fold axis of $3.11 \AA$ which is compatible within the limits of error with Kamb's $6.27 \AA(2 \times 3.11 \AA=6.22 \AA)$. Further studies are in progress.

\section{References}

[1] R. B. Jacobs, Phys. Rev. 54, 325, 468 (1938).

[2] A. W. Lawson and T. Y. Tang, Rev. Sci. Instr. 21, 815 (1950).

[3] J. C. Jamieson and A. W. Lawson, J. Appl. Phys. 33, 776 (1962).

[4] J. D. Barnett and H. T. Hall, Rev. Sci. Instr. 35, 175 (1964).

[5] E. A. Perez-Albuerne, K. F. Forsgren, and H. G. Drickamer, Rev. Sci. Instr. 35, 29 (1964).

[6] R. L. McFarlan, J. Chem. Phys. 4, 60, 253 (1936).

[7] J. E. Bertie, L. D. Calvert, and E. Whalley, J. Chem. Phys. 38 , 840 (1963).

[8] J. E. Bertie, L. D. Calvert, and E. Whalley, Canad. J. Chem. 42, 1373 (1964).

[9] R. H. Wentorf and J. S. Kasper, Sci. 139, 338 (1963).

[10] F. P. Bundy and J. S. Kasper, Sci. 139.340 (1963).

[11] C. Bates, F. Dachille, and R. Roy, Sci. 147, 860 (1965).

[12] B. Kamb, Acta Cryst. 1 7, 1437 (1964).

[13] C. E. Weir, E. R. Lippincott, A. Van Valkenburg, and E. N. Bunting, J. Res. NBS 63A (Phys. and Chem.) No. 1, 55 (1959).

[14] A. Van Valkenburg, Rev. Sci. Instr. 33, 1462 (1962).

[15] G. J. Piermarini and C. E. Weir, J. Res. NBS 66A (Phys. and Chem.) No. 4, 325 (1962).

[16] A. Van Valkenburg, unpublished.

[17] P. W. Bridgman, Large Plastic Flow and Fracture (McGrawHill Book Co., New York, N.Y. 1952).

[18] P. W. Bridgman, Am. J. Sci. 23 7, 7 (1939).

[19] P. W. Bridgman, Pro. Am. Acad. Arts \& Sci. 51, 581 (1916).

[20] P. W. Bridgman, Pro. Am. Acad. Arts \& Sci. 74, 21 (1940).

[21] P. W. Bridgman, Pro. Am. Acad. Arts \& Sci. 72, 45 (1937).

[22] B. L. Davis, Sci. 145, 489 (1964).

[23] P. W. Bridgman, Pro. Am. Acad. Arts \& Sci. 47, 441 (1911).

[24] P. W. Bridgman, J. Chem. Phys. 5, 964 (1937).

[25] B. Kamb and B. L. Davis, Pro. Nat. Acad. Sci. 52, 1433 (1964).

[26] S. Block, C. Weir, and G. J. Piermarini, Sci. 148, 947 (1965).

[27] P. W. Bridgman, Pro. Am. Acad. Arts \& Sci. 74, 399 (1942). 